\title{
KAPLINSKI KAUGUSED
}

\author{
ENE-REET SOOVIK
}

$M$ a võiksin sulguda pähklikoorde ja lugeda end mõotmatu ruumi kuningaks... Lastes Hamletil lausuda neid sõnu, võttis Shakespeare (1975: 44) kokku kontiinumi otsad, mille juurde on ühel või teisel kombel tagasi tulnud mitmed koha ning ruumi üle mõtisklejad hilisematel sajanditel: lähtudes tillukesest ja tihedast punktist, mille piirid on paigas ja materjal lähimeeltega tajutav, on võimalik ette kujutada ja luua kontseptuaalseid kaugusi universumite ja multiversumiteni välja. Põhimõtteliselt kordab Taani printsi mõttekäiku, kuigi pisut ahtamas mõõtkavas, geograaf Yi-Fu Tuan (1981: 149), kes näitlikustab kohakogemuste skaala ulatust, alustades inimese lemmiktugitoolist, mille võimaliku vastaspoolusena pakub välja kogu maa. Kohad on meie jaoks tähenduslikud, meelte abil tajutavad ning võimaldavad reflekteerimist vahetult kogetava üle, oma konteksti leiavad need aga ruumis, mis oma tähenduse just kohtadest ammutab, on kinnitanud teine kohauurimise klassik Edward Relph (1976: 8). Ruum on abstraktsem kui koht, kuid määratleda on seda võimalik nimelt koha ideega vastandades: „Koha turvalisusest ja stabiilsusest teadvustame ruumi avatust, vabadust ja ähvardavust ning vastupidi” (Tuan 1981: 6). Ruum on „amorfne ja kombatamatu ega ole suurus, mida saab otseselt kirjeldada ja analüüsida" (Relph 1976: 8). Kuidas sel juhul kirjutada ruumist üldse või ruumi nendest osadest, mis jäävad „turvalisest ja stabiilsest” lähtepunktist, meid vahetult ümbritsevast kohast, eemale ega ole vahetult silmaga nähtavad või käega katsutavad, kui tegu on luulega? „Tumm verstapostide rivi / on aeg ja lukus on ruum” (Kaplinski 2000: 514; edaspidi Kirjutatud), osutas aegruumi omadustele millalgi Jaan Kaplinski, kes nüüdseks on möödunud oma 75. verstapostist, kui kasutada mõõtühikuna Maa aastat. Tundub, et ruum kogu oma kirjeldamatuses pole tema luules siiski lukku või sõnadele ligipääsmatuks jäänud, vaid avaneb seal üsna mitmel viisil, eelkõige erinevate kaugustesse projitseeritud kohtade toel, mis võivad osutuda üpris mitmekesiseks. Käesolevas artiklis püütaksegi avastada kaugusi Kaplinski värssides, seda, kui kaugel need õigupoolest võivad olla ja mil moel neid kujutatakse või külastatakse.

\section{Kui kaugel on kaugus?}

Ruumi mõõtmatust kogu selle kosmilises ulatuses tõi Kaplinski esile juba oma esimeses luuleraamatus „Jäljed allikal” (1965, edaspidi JA), milles kogu universumit kujutatakse kosmiliste objektide edasiste tasandite orbiitidena. Nende järjestusel ei ole otsa ega äärt: „see on nagu Maa tee ümber Päikese ja Päikese tee ümber Galaktika keskme ja nii edasi ja nii edasi” (JA, lk 55). Maailmaruumi ääretuses aga eristuvad kauged kohad, punktid, mida inimesed on iidsetest aegadest saadik ära tundnud ja nimetanud. Debüütkogu tekstidesse on tähistaevas näha olevast nimeliselt jõudnud planeedid Marss ja Veenus, 
tähed Veega, Deneb ja Gemma, ning tähtkujud „Veemees, / mille all ma olevat sündinud / nagu Byron, Brecht ja Preisi Friedrich" (lk 12). Kui kosmosehuvi taga võinuks algselt aimata kümnendi üldisema retoorika mõju (paralleelina võiks osutada nt Mats Traadi kolm aastat hilisemale „Kassiopeiale”, mille paigutumist perioodi kosmoseparadigmasse on kommenteerinud Jaan Undusk (2009)), ei kao avaramas maailmaruumis leiduva määratlemine ja mõtestamine kusagile astronoomiahuvilise Kaplinski hilisematestki luuletustest, kus üle laotuse ulatub Linnutee ja vahetevahel sähvatavad meteoorid, mõni neist naabergalaktika Andromeeda taustal. Venekeelsetes värssides kumab viimase kõrval Pegasus (Kaplinski 2005: 76; „Sõnad sõnatusse. Инакобытие”, edaspidi SS), ingliskeelsetes otsitakse Sõnni ja Jäära (Kirjutatud, lk 877), maakeelsetes ei saa taevavõlvilt puududa Suur Vanker ja katuste kohal seisab Orion mõõgaga. Mälestusluuletuses August Sangale esineb see muistne vägilane ka maarahva antud nimetusega Reha ja Koot (lk 142). Mõnede tähtkujude kahetise nimetamise võimalust peetakse otsesõnu meeles teiseski tekstis, milles sõbrana esineb „Taeva Sõel mis on see mis Plejaadid” (lk 542). ${ }^{1}$ Tähtedest säravad Kaplinski öötaevas veel Betelgeuze, Aldebaran (SS, lk 20), Põhjanael (JA, lk 56) ja Siirius, kuigi vist mitte Orjatähe nime all; planeetidest võib kohata ka Jupiteri ning Veenust, viimast nii Kuu sulase kui ka rahvalaulude Eha- ja Koidutähena.

Mõned tähed, mis reaalsuses kuidagi kõrvuti ei satu, on spontaanselt nähtavad vaimusilmas: „tähtkujud tulevad meelde / Luik ja Lõuna Rist / miks nemad just / mina ei teagi" (Kirjutatud, lk 519). Luige ehk põhjataeva Suure Risti tähtkuju Suvekolmnurga moodustavad Altair, Deneb ja Veega jõuavad inglise keeles kirjutatud luulet koondavasse kogumikku „I am the Spring in Tartu", kus nende nimetamisest saab vastuvõtmine, inimeste poolt otsesõnu omaks tunnistamine nende ajalis-ruumilisest kaugusest hoolimata: „Arabic and Latin names. / Words of welcome / spoken to the light / which has just arrived / from so many light years away" (lk 896).

Tähtede ja teiste taevakehade kaugus annab ilmaruumile mõõtkava ning sunnib mõtisklema ka suundade üle, mida me muidu üsna teadvustamatult inimkesksetena kipume paika panema: „Nagu uue tähe valgus kusagilt sealt, millest öeldakse „üleval”. Kuigi taevas on igal pool....” (Kirjutatud, lk 750). Universumi ruumilisel kujutamisel võib minna konkreetsemakski kui lihtsalt vahemaade suurusjärgule osutamine, näiteks liikuda kusagile Kuiperi vöö kanti (,valgus toob valge liblika tagasi teispoolt Pluuto orbiiti”, lk 146) või siis tegelda kauguse ja selle suhtelisuse küsimusega täiesti faktipõhiselt ja praktiliselt nagu selles luulekõneluses pojaga: „Kui me kodu juures olime, ütles ta, / et kuu on kaugel, niisama kaugel / kui see koht, kus me käisime. / Ma ütlesin et kuu on palju, palju kaugemal, / ja rehkendasin ise: kui käia / kümme kilomeetrit päevas, kuluks / Kuuni jõudmiseks ikka ligi sada aastat” (lk 578). Just sellesama küsimusega - kui kaugel on Kuu ning kui ligipääsetav see inimesele võiks olla - alustab Kaplinski oma populaarteaduslikku raamatut „Teispool sinist taevast”: „Kuu näib kerkivat üles päris lähedalt metsa tagant, lausa riivavat metsalatvu. Ja ometi ei olnud muiste kellelgi õnnestunud Kuule ligi pääseda ja teda käega katsuda. Nii pidid inimesed endalt küsima, kui kaugel Kuu

${ }^{1}$ Seda kaugete tähtede kohaliku kontseptualiseerimisega seotud kaardistamist tundub olevat kohane kõrvutada Lagle Israeli aastatest 1962-1964 pärit pannooga „Eestlaste muistne tähistaevas" Tõravere observatooriumis. 
ikkagi on" (Kaplinski 2009: 11). Küsimusele, kui kaugele me maailmaruumis põhimõtteliselt üldse näha võime, vastab ta samas raamatus arvuliselt: „Nii näeme praegu tegelikult ruumis kaugemale kui 13,7 miljardit valgusaastat, kuigi võib öelda, et ajas me kaugemale ei näe. Ruumis näeme praegu umbes 46,5 miljardi valgusaasta kaugusele...." (Kaplinski 2009: 147). Piirideks kujunevad siinkohal universumi oletatav vanus ning Maa kaugus aegade jooksul paisunud vaadeldava universumi veerest. Luuletused kosmiliste kauguste mõõdistamisel siiski nii kvantitatiivseks ei muutu, seal nenditakse lihtsalt: „valgus on liiga kaugel / valgus / valgusaastate kaugusel” (Kirjutatud, lk 41).

Valguse ja tähtede ekvivalentsusele eesti luules on selle varasemat perioodi käsitledes viidanud Õnne Kepp, kes, kuigi nentides, et talumaastik ja taevalaotus moodustasid ühtse ilmaruumi, vaatleb toonaseid täheluuletusi siiski eelkõige metafoorsetena, „romantiliste ideaalabstraktsioonidena” (Kepp 2012: 190-191). Kaplinski tähed aga ei moodusta tasapinnalist kaant inimeste maailma kohal ega ole niisama kaunid kaeda ja üllad laulu sisse seada. Tema kosmos on reaalne ja ruumiline ning astronoomia toel toob ta tähistaevasse sügavusmõõtme ja oma luuleruumi kaugusmõõtme mastaabis, mida maapinna horisontaaldimensioonis oleks võimatu saavutada.

\section{Mägede ja merede taga}

Kosmilised vahemaad võivad jääda küll ületamatult ja hoomamatult suurteks, kuid on siiski teaduslike vahenditega mõõdetavad. Kaplinski luuletustes rullub nende kõrval väikese, kuid selgepiirilise alana lahti teinegi käegakatsutamatu ja põhimõtteliselt veelgi ligipääsmatum kauguste liik: ruum, mis paistab paiknevat kusagil eemal, jagavat maapealsega mingeid geograafilisi tunnuseid, kuid mis oma kaardistatuse ja konkreetsuse astmelt jääb kosmosest ebamäärasemaks ja salapärasemaks. See on kõrgetest mägedest ümbritsetud kauge piirkond, mis meenutab muinasmaad, muinasjuttude tegevusvalda, mida folklorist Risto Järv on Wilhelm Nicolaisenile ja Heda Jasonile viidates kirjeldanud kui üldreeglina nimetut, topograafiliselt üksnes minimaalselt skitseeritud „fundamentaalselt akartograafilist ruumi” (Järv 2008: 275-276). Jasoni visandatud skeemis on muinasmaa piiritletud saareke, mis asub siinse maailma ja sealpoolsuse vaheruumis umbmäärases kauguses ja mille puhul on olulisim mitte essents, vaid erinevus - tõik, et tegu ei ole lugusid vestva kogukonna kohapealse tegelikkusega (Järv 2008; 2010: 630). Kui sellises seitsme maa ja mere taga aset leidvas muinasjutus mõni konkreetne kohanimi esinebki, siis sümboliseerib see kaugel asumist ja määratlematust: jutuvestja kogukond on seesugusest paigast ehk küll kuulnud, kuid ei tea sellest tõenäoliselt midagi lähemat ega kujuta seda endale kuigi hästi ette (vt Järv 2008; 2010).

Kaplinski n-ö muinasmaa on samuti selgesti piiritletud ja seda tihtipeale ääristavaid mägesid võib katta lumi („kõik kes elasid ja armastasid / lumiste mägede varjus / on läinud oma teed" (Kirjutatud, lk 38)), nii et ilmselgelt ei ole tegu kohaliku kuppelmaastikuga. Eristavaks piiriks võivad mäed osutuda muidugi ka puhtmetafoorselt, nii heidutavamas ja lootusi nurjavamas (,ja ette su otsimise / taas kummuvad mägede turjad", lk 125) kui ka helgemas ja küllap kainele ratsionaalsusele vastanduvamas tähenduses („Meel unus mä- 
gede taha / hea uni silmile vajus", lk 32), kuid muinasmaa iseenesest ainuüksi metafoor ei ole. Esineb isegi mägedega seostuvaid toponüümilisi viiteid, nagu näiteks „tuli Andidest” (lk 37), kuid need ei näi toimivat mitte geograafilise tegelikkuse mimeetilise kujutamise tööriistana, vaid pigem Jasoni osutatud muinasjutuliselt võõra kauguse markeerijatena, nii et luuletus jätkub: „kas tead neid laule / kaugelt maalt / kas tead seda kes oli pime / aga ometi nägi / mägede vaikust ja rahu" (lk 37). Mägedel leiab aset ka otseselt müütilise mõõtme sündmusi, nagu fööniksi tuhast tõusmine: „oi koitu äkki nii noore / linnu silmades muistsel mäel" (lk 118).

Muinasjutumaailma jõutakse tavaelu piire ületades (Järv 2010), ja kui Kaplinski muinasmaa-saarekese tunnebki tihtipeale ära just piiritleva funktsiooniga mägede kaudu, pole see piir siiski hermeetiliselt läbimatu ning selle tagant võib tulla signaale veel mingist muustki ruumist. Lugejaga ühisest argimaailmast eemale projitseeritud luulemina lõikavad mäed ära ka mingist teisest, tema jaoks omakorda eemal asuvast vallast: „kauguses / näen üht naist lahtiste juustega / ta nutab ta seljas on must rüü / aga mäe tagant naeratab päike” (Kirjutatud, lk 48); „sinimägede tagant kajab kellegi laul” (lk 39); „tuul millal tuled mu juurde / või ka sulle liig kõrged on mäed” (lk 34); „üle mäe keegi kutsub mina vist olengi seal” (lk 70); „Sõjamehed laulsid lõkete ääres / neiud laulsid minnes allikale / ja pilved rändasid üle mägede" (lk 40). Nii on neis tekstides tegu topeldatud kaugustega - eemalasuvas ruumis viibija jaoks on mägede taga omakorda midagi kauget.

Mäestik pole aga ainuke kauge maa markeerija. Kaugustele teistsuguse, eksootilise maastiku mõttes viitab kõrb, mis võib apokalüptilise alatooniga kujutelmades mägedega kõrvuti esineda: „kõrbed unustavad oma nime / ja värisedes kummarduvad mäed / selle ees kes lausub viimase sõna" (Kirjutatud, lk 50). Biotoobina aga osutub kõrb paratamatult geograafiliselt lokaliseeritumaks. Kandes küll kauguse ja kuivuse konnotatsioone ning omandades sellega teatava abstraktse sümbollaengu, asetub kõrb paika tegelike kompassikaarte suhtes („tuul üle kõrbe tuleb tasakesi / ja linnud Põhjast uinuma jäid puudel” , lk 97) ning võib maakaardil referentsiaalset nime omada (,NAMIB KALAHARI / vihm saab auruks enne kui sadada jõuab", lk 128). Kõrb kuulub vähem väljamõeldud maailma ja rohkem geograafilisse tegelikkusesse kui mäed, kuid meie teadmised geograafiast paigutavad kõrbemaastiku paratamatult kaugele eemale, luuletaja kodukogukonna jaoks sellisesse ruumi, mille kohta vahetuid kogemusi ja teadmisi on paljudel pigem vähem kui rohkem.

Lisaks mägedele asuvad muinasmaad traditsiooniliselt ka merede taga. Kui mäed seavad piire ja sulgevad silmapiiri, teeb meri vastupidist: avab tee kauguste suunas, mis avarduvad potentsiaalina kuni lahtise silmapiirini välja. Kaplinski luulemeri kuulub küll tihti veel reaalsemasse maailma kui kõrb ja on koduse või kaugema kaardi pealt selle võrra leitavam, ent temaga koos lainetab mõnigi kord samaaegselt ka müütiline antiikne muinasmeri, thalassa või thalatta (Kirjutatud, lk 420, 735, 799). Mere äärde jõudmine võib tähendada tuttava (mais)maailma piiridele pürgimist, mida eurooplase vaatepunktist markeerib eelkõige Atlandi ookeanini jõudmine: „laevata lemmikuta tiibadeta maa lõpus / vastu Atlandi osavõtmatust” (lk 242), „Minus köeb seesama kihk Atlandi poole, / piiride poole, mis ometi aina kaovad ja katkevad" (lk 667); „LONGING TO SEE THE ATLANTIC, the last frontiers of the continent” (lk 911). Kui mäed on piiriks, siis meri on jagamatu ruum teisel pool piiri, rannajoont, 
mis võib olla avara üldistusena inimolu ruumiliseks taustaks (,said selle elu endale kanda / käid mööda piiri käid mööda randa”, lk 113) või seda inimelu mingi konkreetse, näiliselt lausa meelevaldse pidepunkti abil kuskile paigutades: „Ütlemata sõnades leekideks põlen / mina valgeks tuhaks merikarpide tolmuks / Connemara rannal / hing sina liblikas kuhu lähed sina kas väsid / mitme mere kohal / maade kohal mis on võõrad pilvede palistuses" (lk 242). Meri ise on aga tõepoolest avatud ja vaba, jagamatu ala, millel piire ei ole ja mille lõppu pole näha: „Mõtleme parem merele. Ning et on midagi suuremat kõigist / küsimustest. / Midagi, mis ulatab üle iga piiri” (lk 735). Nagu mägedegi tagant võib ka merelt tulla tundmatuid teateid ja kutseid: „mis helinaid merelt sa kuuled / vihaselt käivad tuuled / üle kodu madala ranna”, ja seejärel „siis kaugelt kui kutse kõlas / ma läksin ja võtsin mõlad / ning lükkasin lootsiku vette” (lk 33). Mere enese mühagi tähendab iseenesest kaugust: „kaugete tõusude kohin nagu see / mida laps kuuleb merikarbis ainult võimsam ja valjem" (lk 39).

Kui mägi on see, mis kaugusesse ei lase, on meri see, mis ise kaugust kehastades sinna ahvatleb. Kaplinskilt võib leida lausa traditsioonilist meremehejuttude kaugemaaeksootikat („longing for open seas and fresh winds, / smells and colors of foreign lands: / cedar of Lebanon, balm of Gilead, / silk of China and girls of the South" (Kirjutatud, lk 907)), kuid seda esineb siiski vähe. Ranna taha piiritagustesse kaugustesse jääb tõepoolest mõneti mütologiseeritud lõunasuund ja lõunamered, ent sinna liikumiseks ei astuta laeva pardale, vaid järgitakse pigem rändlindude teed. „[I]kka ikka lõuna poole” (lk 160) on intertekstuaalse viitena omal kohal ning sookure vaatepunktist kinnitatakse, et „mu kodu on äraigatsus / ja lõunamaa mered ja liivad” (lk 545). Inimeste linnurändeteadmiste baasilt käiakse mõtetes kaasas rändeteekonnal, millel on teadaolevad geograafilised sihtpunktid: „Meie ei lähe Aafrikasse, kust me oleme pärit, nagu lähvad / pääsukesed ja toonekured” (lk 820) või „Kuni nad on, kuni nad tulevad kevadel tagasi, / on maailmas veel korda ja lootust, on veel alles need haprad linnulennu-niidid, / mis seovad meid Egiptuse, Sudaani, Kongo ja Kapimaaga" (lk 764).

Selline, lindudele lubatud, kuid inimestele - eriti Nõukogude perioodil, millest paljud vaadeldavad tekstid pärinevad - mitte nii hõlpsasti kättesaadav lõunamaa seostub ühest küljest tuntud ja teatud eksootilise ja lõõgastust lubava üldistatud teisal-troobiga, mida esindab palmirand kui selline: „ma tean kus on värvid ma tean kus on merede väravad ma tean maavärinate käekirja ja palmide kannatlikku meelt / lõunamaa leiges tuules" (Kirjutatud, lk 160). Teiselt poolt markeerivad seda Kaplinski luules sageli kauged ja konkreetsed saared: näiteks ukumasinglikud Matahiva (lk 90) ja Rapanui (lk 85) Polüneesias, nende kõrval aga ka sellised, mis mõnusa soojuse tarvis asuvad juba liiga suurtel laiuskraadidel ja seega kaugemaapuhkuse rannarõõmudega karmi kontrasti satuvad, ent sellest hoolimata võivad hinge loverännakute eesmärgiks olla: „kuhu sina tahtsid lennata kuhu / siis mujale kui lõunamerele ei mitte / sinna palmide ja tüdrukute juurde ikka / kaugemale lõunasse sinna kus mõned / üksikud saared on eksinud Vaikse / ookeani vaikimisse Falkland Macquarie / Kerguélen Bouvet" (lk 418). Eriti Kerguelen ja Falkland tunduvad olevat tähenduslikud locus'ed Kaplinski mõttelistel merekaartidel ning seda nimekirja on ta nimetanud olulisemateks loitsudeks poeemis „Hinge tagasitulek": „Need on teispool maakera, on meie antipoodid, minek nende juurde 
tähendab minekut teise maailma või selle maailma pahupidi, jalad ülespidi pöördumist" (Kaplinski, Vercingetorix...).

Tegelikud lõunamaal käigud, kui need aset leiavad, toimuvad või jäävad toimumata otsustavalt ärilisemas ja organiseeritumas keskkonnas: „Ei lennata lõunasse / nagu need soomlased / kõrgel taevas meie peade kohal / aurinkomatkoilla” (Kaplinski 1998: 12; „Öölinnud, öömõtted”, edaspidi ÖÖ). Risto Järv (2010) on küll osutanud tähelepanuväärsetele sarnasustele muinasjuttude ja tihti muinasjutulise elamusena reklaamitavate eksootiliste turismireiside vahel ning hariliku ja ebatavalise keskkonna vahelise piiri ületamisele mõlema puhul, kuid isegi siis, kui nad kuuluvad unistuste ruumi ja seostuvad pahupidise teispoolsusega, ei saa selliseid kaugeid saari, mida Kaplinski juba nimepidi katalogiseerib ja tuttavate paikadega pigem kõrvutades kui vastandades suhestab (kõige kondenseeritumaks näiteks on pea ainuüksi saarenimedest koosnev „Kythera, Milos, Kea...” (Kirjutatud, lk 608), mis Vahemerelt Kihnu, Ruhnu ja teiste Eesti saarte kaudu Vaiksesse ookeani ja taas Kerguelenini jõuab), siiski ainuüksi muinasmaailmaks pidada. Need on osa geograafilisest, ajaloolisest ja poliitilisest reaalsusest.

\section{Koloniseerimine ja konflikt}

Kaardid, nagu me neid tunneme, hõlmaku need siis kaugeid või lähedasi alasid, on selliseks kujunenud ajaloo vältel. Ökokriitik Lawrence Buell on osutanud, et maailma ajalugu on olnud ruumi kohaks muutmise ajalugu: kaugete maade asustamise käigus loodi varem vormitust ruumist tähenduslikud kohad, ent varem asustatud piirkondade koloniseerimise protsessis võisid sealsed esmaasukad kaotada nii ruumi, mida olid enda omaks pidanud, kui ka kohad, mis nende jaoks tähenduslikud olid olnud (Buell 2005: 63-64). Eespool mainitud Falkland ja Kerguelen kuuluvad eurooplaste jurisdiktsiooni alla ning on saanud oma loitse loovad nimed inglastelt ja prantslastelt: vastavalt Falklandi vikonti auks, kes sponsoreeris kapten John Strongi mereretke sellesse piirkonda 1690. aastal, ning maadeavastaja Yves Joseph de Kerguelen-Trémareci järgi, kes 1772. aastal ise saartele pärale jõudis. Nii pole kaugustesse küünitumine läbi aegade olnud sugugi süütu; piirideta mereavarused osutuvad poliitiliseks vallaks ja saared majandusliku kasu allikateks, mille kunagised kolonisaatorid juba ammu enda omaks kuulutasid, ning 1982. aasta sõda Ühendkuningriigi ja Argentina vahel Falklandi saarte pärast pole elavast mälust veel praegugi kustunud.

Kaplinski ei kipugi kaugeid saari üksnes mütologiseerima, vaid on ka luuletajana ajaloo reaalsest käigust täiesti teadlik, küsides: „miks me ei teinud midagi ei öelnud midagi / kui vaalapüüdjad jagasid viimased mered ja piprakaupmehed viimased saaristud" (Kirjutatud, lk 162). Ekspansiivset koloniaalajalugu, ${ }^{2}$ mille käigus kaugeid alasid uute nimede ja mõistetega üle kirjutatakse ja seeläbi kolonisaatori huvides kodustatakse, puudutavad mõned Kaplinski krestomaatiliste luuletekstide seast. Nende vaatepunkt kuulub impeeriumi keskmest vaadates äärealade elanikele, kes kaugelt tulnute tõttu

${ }^{2}$ (Post)koloniaalteemat Kaplinski luules on kommenteerinud kirjanik ise, nt essees „Vercingetorix kõneleb ordumeistriga” (Vercingetorix...); kirjandusteadlastest on seda teinud nt Thomas Salumets (2014a, 2014b, 2014c) ja Margus Lattik (2014). 
on omased kohad kaotanud või neid kaotamas, paigapealsete perspektiivist hoomatakse ka vallutuste ulatust. Nii lausub arvernide pealik Vercingetorix Rooma impeeriumi laienemise kohta: „Olgu su sõdureil, kaupmeestel ja sulidel / ohutu tasane tee / Ultima Thuleni / ja Styxini välja” (lk 253), hõlmates elavatele hingedele teadaolevat maailma niikaugele, kui see siinpoolsuses ulatub, ja kaugemalegi veel. Põlisameeriklastest jäävad nende maale maha ainult liiga pikad nimed, ent geoloogilises mõõtkavas osutuvad nagunii ajutiseks ka maad ise, inimpopulatsioonidest rääkimata: „Rannad / paistavad kaugele merele. Verevas, / verises kumas. Enne meid, pärast teid / ehitavad korallid uusi saari ja maid. [---] Kes teadis avastada meid ja meie maid pärast meid endid?" (lk 256).

Indiaanlased räägivad oma maadest, mis ei moodusta riiki meie praeguses tähenduses. Tuan (1981: 149), kes nimetab kodumaad oluliseks kohatüübiks oma eespoolmainitud koha- ja ruumiskaala keskosas, defineerib seda põhimõtteliselt piirkonnana, mis jaksab ühe rahva ära toita, ning pühendab sellega seotud kodupaigakiindumusele ning paiksusele terve peatüki. Sellist, kiindumustundega tervikuks seotud, kuid koguulatuses meeltega tajumiseks siiski liiga avarat, maakaardina lahti rulluvat kodumaaruumi laseb Kaplinski paista näiteks kartograafi linnulennulisest vaatevinklist, ehkki kujutab pigem kaardi kustutamist kui uue koostamist. Tema Muinas-Eesti ruum teiseneb kaugusesse vaataja pilgu ees ning koos nimede kaoga kaovad sealt ka nende referendid: „üle mere ja latvade näed all kaovad nimed ja maad / vaata Alutagust ja Vaigat kuni veel saad" (Kirjutatud, lk 134). Ühes ingliskeelses luuletuses (lk 895) järgib ta see-eest umbes kahesaja kilomeetri pikkust bussisõitu Pärnust Tartusse mööda maanteed, mida palistavad tee peale jäävate kohtade nimed. Hoiatuse paigutab selle lumega kaetud teekonna rahulikkusse eelnevalt Pärnu teatris nähtud iiri näidend, Brian Frieli „Tõlkijad”, milles Iirimaa gaelikeelseid kohanimesid Briti sõjaväe abil ingliskeelseteks ümber pannakse ning mida näitena käsitleb ka Buell (2005: 79-80), kui kirjutab kohakiindumuse manifestatsioonidest koloniseerivates-globaliseeruvates tingimustes.

Kolonialismikriitikat sisaldas juba „Jäljed allikal”, ehkki esialgses kontekstis võis see esmapilgul paista mandunult magavate kapitalistlike kauguste sarjamisena. Ideoloogiliselt kahtlastena tähistatud piirkondi esindavad seal suurlinnad, mis Kaplinski luuleloomingus tihti ette ei tule. Kõige tugevama laenguga on nende seast ootuspäraselt New York, aga - taas kord katalogiseerivalt ja kaardistavalt - „magatakse idarannast südamaani, / Rio de Janeiros, Santiagos ja Torontos" (JA, lk 24). Ilmselt põlisasukatest ärkvelolijad Uues Maailmas, „minu rahvas seal kuskil / Labradori ja Tulemaa vahel” (lk 25), paiknevad pigem äärmuslikumates ja vähem urbaniseerunud tingimustes Ajakutšos või Jukatanil (lk 24). Hilisemates tekstides ajastuoptimistlik sotsiaalse maailma teisenemise ootus, kus ,jänkide kõrkus litsutakse orgude põhja” (lk 25), enam kuigivõrd esile ei tule, kusagil kaugel viljeldava traditsioonilise elulaadi, näiteks hantide oma (Kirjutatud, lk 556-557), heaks kiitmine aga küll.

Teine, oma esialgses manifestatsioonis Nõukogude olude kohta üsna tavapärane teema esikkogus oli Teise maailmasõja pinnalt tõusev sõjavastasus. Sellest on hiljem püsima jäänud holokausti aspekt, mis samuti kohanimeliseks konkretiseerub: lähemal Salaspilsiks (Kirjutatud, lk 365), kõige laetumalt aga Auschwitziks (nimi, mille praegu kehtiv poolakeelne esinemiskuju Oświęcim taas kord viitab kohtade poliitilisele ülekirjutamisele eri aegadel), 
mis asub ühtaegu piisavalt kaugel ja ometi piisavalt ligi selleks, et oma kodugi võiks sinnapoole kaldu olla (lk 276). Vägivalla ja genotsiidi globaalset ulatust tähistades seisab Auschwitz teisal kõrvuti Owerriga Nigeerias: „Põlenud tapetud lapsed / avavad silmad meie pimeduses / lapsed Auschwitzist Owerrist" (lk 244), tuues oma vältimatute assotsiatsioonidega lähemale kirjutaja kaasajal teisel mandril aset leidvate vägivallasündmuste tähenduse. Nigeeria kodusõda (1967-1970) paistab ülepea olevat olnud üks teravamalt teadvustatud poliitilisi konfliktiolukordi, mis Kaplinskile kusagil kaugel toimuvana on oluline tundunud ja samas ka kodus relevantne paistnud, moodustades korduvalt ühe poole lokaliseeritud päevasündmusepaarides: „Niigeri jõgi Biafra laht rinnas vasakul pool / mõlema Kennedy kalmud onu Mardi ja vanaisa kõrval” (lk 178); „et meri ei uputa asjata tiirupesi et itaallased ei söö asjata pääsukesi lapsed ei põle asjata oma voodites ja onnides et halvatud ei ole asjata halvatud Biafra asjata Biafra ja Bangla Desh Bangla Desh” (lk 153); „uudist / on vähe Gowoni mehed ründavad Enugut / esimees Mao pildi taha on siginud lutikad" (lk 174).

Välismaal aset leidvaid rahvusvahelisi sündmusi jälgitakse meedia vahendusel ja ehk võiski Biafra 1960. aastate lõpu poole päevakajaliste teemade seas prominentsel kohal olla (samal ajal kui 1968. aasta paiku Euroopas aset leidev jääb üsnagi ootuspäraselt pigem varju). Ent kaugesse maailma jagub hilisematelgi kümnenditel agressiooniakte ja ähvardusi, pingeid, pahesid ja humanitaarkatastroofe, millest eelkõige raadio - ja mitte üksnes ühte ideoloogilist hoiakut esindava kanali - kaudu teada saadakse: „Raadio / rääkis, et USA laevastiku löögiüksus / suundub Nicaragua ranniku lähistele" (Kirjutatud, lk 651); „BBC World Service and RFE are speaking / of conflicts, conferences, conventions and alliances / and millions of people starving and dying in Ethiopia / and sometimes of a boatful of refugees / dying of thirst or killed by pirates / somewhere in the Southern seas" (lk 921). Seega võivad unistuste lounamered karmis poliitilises reaalsuses osutuda riskantse pagulastegelikkuse näitelavaks nagu tänapäevalgi. Kokkuvõttes ei tundu kauge maailm, niivõrd kuivõrd seda defineerivad inimkogukonnad ja nendevahelised suhted, kuigi ahvatlevana, vaid on pigem taustaks tasahilju ligi hiilivatele maailmalõpumärkidele, mille seas võib oodata kõike järgnevat: „Big powers / insulting one another, serious crises, / disarmament conferences in Geneva, / drug addicts in Washington, dissidents in Moscow, / hunger in Sahel, terrorism in the Middle East" (lk 915). Meedias tähtsustatud kohtade ühiskondlik ja poliitiline tähenduslikkus jätab nende potentsiaalselt meeltega tajutava poole ilmselgelt varjule, ning tõepoolest, ka Buell (2005: 65) refereerib nüüdismaailma kohatajuskaaladest kõneldes kohafenomenoloog Edward Caseyt, kes osutab kohateooria elavnemisele XX sajandi lõpus, kuid peab silmas pigem sotsiaalset kontekstualiseeritust kui füüsilises keskkonnas paiknemist, mida armastas rõhutada nüüdseks klassikaks muutunud 1970. aastate fenomenoloogilise geograafia laine eesotsas Relphi ja Tuaniga.

Kriisipiirkondade problemaatikaga seostuvaga tuli kunagisel riigikogulasel Kaplinskil kokku puutuda üsna otseselt, kuigi jõulisest osalemisest debattides tundub ta luule põhjal pisut distantseeruvat: „Kolleegid Tallinnas arutavad, kas oli õige Iisraelist relvi osta või ei” (Kirjutatud, lk 817). Jõulurahusel ajal aga määratleb Lähis-Ida siiski pigem sealne loodus oma ilmaolude ja elustikuga ning tekivad küsimused, millele poliitikasaated vastust ei anna: „Mis ilm on praegu seal Palestiinas? Mis seal praegu õitseb?” (lk 698). Mõne 
teise kandi puhul on natuke abi ilmateatest, mis võib näiteks kuulutada, et „Lõuna-Skandinaavia kohal on suhteliselt püsiv kõrgrõhuala mis laguneb” (Kirjutatud, lk 165). Õhumasside liikumine tekitab ühendusi kaugemale jäävate aladega: „cyclones come across Scandinavia” (lk 886); „välkude karavanid mis tulevad üle Atlandi” (lk 169), ning kaugustega seotud ilmamuutust võib kogeda ka omal nahal ja koduse taeva all, näiteks siis, kui „vihm veereb ära / Venemaa poole" (ÖÖ, lk 59). Tuuled, mis lõhnavad Vahemere, Šveitsi või Küklaadide järele (Kirjutatud, lk 165), võivad omakorda kaugelt kohale toimetada lõhnaaistinguid, mis muidu on üksnes vahetult tajutavad, ning anda ootamatult märku kauguste meelelisest küljest.

\section{Rännud unes ja ilmsi}

Peale efemeersete lõhnade liigub kaugustest lähiruumi ka materiaalsemaid objekte, näiteks keskküttekatla jaoks mõeldud Sileesia süsi (Kirjutatud, lk 609) või Fidži saartelt läkitatud postkaart (lk 535), ning sealt võib kohale saabuda Prantsusmaa president isiklikult (lk 789). Seega on võimalik ka vastupidine - kaugeid paiku külastades need ajutiselt omaenda lähestikuks ${ }^{3}$ muuta. Nii saab luuletaja siis, kui Soome raadios räägitakse 1989. aastal toimunud Tiananmeni veresaunast, seda seostada varasema isikliku ruumikogemusega: temagi on Taevase Rahu väljakul käinud ning suudab seda kauget kohta meenutada, muuhulgas mäletades sealset tolmu, mis võis olla pärit kas kohalikult ehitusplatsilt või siis eemal asuvast Gobi kõrbest (lk 794). Sarnaselt kujuteldava muinasmaaga siseneb sellessegi luuletusse topeldatud kaugusmõõde: ühest küljest asub Tiananmen kirjutaja ja lugeja hetkeperspektiivist vaadatuna eemal, teisalt esineb see mälestuses lähestikuna, mille suhtes kaugustesse jäävad hoopis teised kohad.

Kusagil mujal asuvatest reaalsetest paikadest luuletas Kaplinski samuti juba päris varajastes tekstides. Esikkogus olid sellisteks ärakäimisruumideks ilmselt võimalustest johtuvalt pigem Nõukogude Karjala ja Siber, mille eksootilisust sai ideoloogiliselt korrektselt raamistada huvina suure kodumaa vastu. Ometi on hiljem lahti kirjutatud koloniaalteema peidus juba siingi: veel struktureerimata loodusruumile nimede andmises kajastuv alistav ekspansiivsus väärib optimistlikku äramärkimist, kuid seda pigem burjaatide kaua kestnud asustust tunnustades kui Vene tsaaririigi laienemist kiites: „Kes olid need esimesed, kes panid neile maadele nimed? / See oli suur töö, nüüd on ta tehtud. / Bai-kul, Angara, Irkut, Selenga, Munku-Sardõk” (JA, lk 53). Paralleel hilisemate tekstide indiaanlaste ning nende maastikesse kirjutatud pikkade nimedega ei oleks siinkohas sugugi kohatu. Venemaa suhtest Siberiga on etnoloog Aivar Jürgenson (2007: 34) kirjutanud: „Jermaki vallutust hakati võrdlema eurooplaste vallutustega Uues Maailmas, territoriaalses ekspansioonis nähti midagi püha. Siberist sai venelaste jaoks „meie Peruu ja Mehhiko”...”, seejärel meenutab Jürgenson ka Jermaki sarnastamist Cortézi ja Pizarroga

\footnotetext{
${ }^{3}$ See Johannes Gabriel Granö termin katab lähedalasuvat intiimset maailma, mille kontekstis võime tajuda geograafilist objekti kõigi meeltega. Granö ei osuta, millal täpselt lähestik maastikuks üle läheb; maastikku võiks tajuma hakata ehk saja või paarisaja meetri pealt, maastiku kaugem piir aga ulatub silmapiirile, kus maa ja taevas kokku saavad (Karjalainen 2002: 132).
} 
Nikolai Karamzini poolt. Kaplinski teeb aga teistsuguse kõrvutuse, omistades Baikalile meie kohamuistendites esinevat järvede rännusoovi ja motivatsiooni, „nii nagu järved muiste rändasid / ära inimeste musta pesu või tuleva talve eest" (JA, lk 15). Selline kauguste kahandamine erinevate maailmajagude järvi üksteise peale projitseerides seisab kõrvuti järjekordse topeltkauguse tekitamisega kõrbe abil: „Pilved lähevad lõunasse, sulama tühjaks / kusagil enne Gobit või Takla-Makani” (lk 15).

Nõukogudeaegses Burjaatias käib Kaplinski ka ohtralt tööstust, tehnikat ja igasuguseid ametiasutusi täis linnas, mis on tema puhul üsna haruldane keskkond. Loodusruum selle ümber aga kajastub see-eest igati tuttavate elementidena, lisades pildile nii muinasjutulist kui ka kosmilist - linna ümbritseb „[m]ägede terendus taamal” (JA, lk 55) ning selle „kohal sirab Põhjanael” (lk 56). Piiride avanedes muutuvad luulesse jõudnud reisid üsnagi ootuspäraselt pikemaks ja sagedasemaks, kuid linnakogemusi ei kipu nad endas kätkema isegi siis. Teine markantne mulje sagivast suurlinnast pärineb kümneid aastaid hilisemast ajast, Prantsusmaal kirjutatud Pariisi-tsüklist, kus rahvarohke linn traditsioonilisel modernistlikul moel „sumiseb, müriseb ja sahiseb, / tiirleb ja sagib nagu ratastel sipelgapesa" (Kirjutatud, lk 798). Siinkohal, nagu ka sama kimbu Bretagne’i paigutuvates luuletustes, rõhutatakse eriti väljastpoolt tulnu ja äraolija vaatenurki. Teine eemal asuv luulepaik - Soome - ei tule esile nii võõrapärasena, olgu siis põhjuseks geograafiline lähedus või loodustaustade eelistamine linnale. Soome lahe hall vesi see-eest omasena ei tundu, oma meri on paradoksaalsel kombel „kuskil / mujal, Kreeka, Türgi, Hiina või Kalifornia rannikul" (lk 838). Uus avaram tervikruum on poliitiliselt ühinev Euroopa, mille üle arutletakse Budapestis (SS, lk 53) ning mis tõmbab jooni Kohila ja Brüsseli vahele (ÖÖ, lk 46).

Välismaised ruumid on ka kaugete keelte ruumid: Burjaatias räägitakse raadios „võõraid ja tuttavaid keeli” (JA, lk 56); Bretagne'is see-eest vaikitakse bretooni keeles (Kirjutatud, lk 799). Huvitavate kontrastide abil loodud keelelist kaugusekujutust pakuvad võrukeelsed haikud, mille koduse kohalikkusega assotsieeruv keelematerjal on korrastatud Jaapani valemi kohaselt; selles hübriidses ruumis esinevad Šiva tempel, taimed ja loomad viitavad aga hoopistükkis India subkontinendile, mille maastikule veavad piiri varajases luules vaid muinasmaal esinenutega sarnased mäed: „Päävä helk kavvõh / lumitsil mäkil - hekih / kõllane äitse” (Kaplinski 2008: 94); „Üts valev pilv viil / kavvõst pümme mäe takast / paistus aknahe" (lk 95). Keele abil on võimalik käia ka mõttelistes kaugustes, lastes end sinna kanda teisel keelel ja teisel keelekasutajal: Paal-Helge Haugeni luule tuletab meelde Bygdøy poolsaart Oslo lähedal ja merd selle taga (Kirjutatud, lk 744); Gary Snyder on luuletanud, vaadates tormi Nevada Valgetes mägedes (lk 627), Harry Martinson aga Helgolandi ja Utshima lahingutest (lk 569); lühikesed luuletused võimaldavad kokku panna terve Hiinamaa (lk 684). Salvestatud keel muudab võimalikuks kokkusaamiste vahendamise selle üleskirjutanutega: hieroglüüfid aitavad „üle ruumi ja aja sinna teie juurde, / Su Dong po, Bo Ju yi, Tao Yuan ming" (lk 843) ning Tartus kirjandusmuuseumis ja raamatukogus võib kohtuda nendega, kes on surnud või väga kaugel (lk 686).

Kaugused ei tarvitse saada jäädvustatud mitte üksnes sõnas, vaid ka pildis, näiteks Istanbulis tehtud fotodel (Kirjutatud, lk 842), samas ei vaja mäles- 
tused tingimata dokumenteeritud pildilist tuge. Huvitav on see, et iseseisvalt mällu kerkivad pildid kaugustest kipuvad Kaplinskil seostuma veega: mäletada võib iseennast libisemas järve Karjala kannasel (lk 740) või poega sukeldumas Vahemere selgesse türkiissinisesse vette (lk 788). Kodumaa reaalsusse sekkuvad mälestused Lõuna-Hiina merest, mille tõttu näib, et „lapsed vaatavad pilusilmadega / ja vint pärnapuus laulab valjusti / kantoni murdes" (lk 824). Lihtsalt mälestustes kangastuva kõrval ilmutavad kauged kohad end ka unenägudes: Halmahera saar Indoneesias ilmub seal näiteks kasvuhoonekujulise mudeli kujul (lk 741); unedes on üldse viibitud saartel, ning Hiina, Kreeka ja Lääneranniku elupuumetsad, kuigi need on ilmselt olnud tegelikud reisisihid, seisavad selliste unedega võrdsustatult kõrvu (lk 816). Lõpuks võib uni tõotada ka veel toimumata reise, näiteks laenatud lennukiga Kölni lendamist (lk 795), või unenägija soovida, et lemmiksihid unes end ilmutaks („tahaks minna ära / ja veel mõni kord käia Lõunamere saartel”), kuigi unenägu pakub vaid reisitõrkeid (lk 830). Teisal paigutub igatsetud lõunamaa aga kõrvuti noorusega, mis kipub pääsmatult käest kaduma (ÖÖ, lk 20).

Kui püüda Kaplinski kirevatest ja erilaadilistest kaugustest kokkuvõtet teha, võiks lähtuda Franco Moretti (1999: 13) lihtsast kirjandusgeograafilisest soovitusest pärast huvipakkuvate tekstijoonte kirjapanemist tulemuseks saadud kaarti uurida ja vaadata, ega silma ei jää seaduspärasusi või mustreid, mis esialgsele infole ka midagi juurde võiksid lisada. Siinne kaardistamine näitas, et kindlasti pole jõustunud algusaegade pessimistlik prognoos, milles pähklikoor muutuks aja jooksul läbistamatuks ja ruum tõesti lukustuks, jättes alles vaid kitsa koha: „su maailm on siis nii väike aken voodi ja ahi” (Kirjutatud, lk 47). Provisoorselt nelja suurema alapealkirja alla liigitatud kaugused ulatuvad üle laia skaala, kattes isiklikult kogetut (või põhimõtteliselt kogetavat) nii vahetult kui ka mälestuste või unistuste kaudu esitatuna; vahendatut nii kirjanduslike kui ka uudistekstide esituses, ja lisaks sellele poliitilisi, müütilisi ja kosmilisi kaugusi - hamletlikuks mõõtmatu ruumi üle sõnaga valitsemiseks on seda kõike päris piisavalt. Mis aga esmapilgul ehk välja ei paistnud, oli see, kuivõrd paljude juurde nende erinevate kauguste seast hakkasid teed hargnema juba debüütkogust, heites edasi kulgedes kõrvale lähtepunktide ajastutüüpilisi või standardsevõitu kujundeid ja hoiakuid ning koondudes ajapikku autori enda seatud isepäisteks sihtideks. Käidud on neid teid pikalt, aga käia võiks veelgi - Tuani loetletud avatust, vabadust, kuid miks mitte ka ähvardavust paistab selles luuleruumis küllaga jaguvat.

Artikkel on valminud seoses uurimisteemaga IUT 2-44 „Enesekirjeldusmehhanismide semiootiline modelleerimine: teooria ja rakendused”. 


\section{Kirjandus}

Buell, Lawrence 2005. The Future of Environmental Criticism. Environmental Crisis and Literary Imagination. Malden-Oxford-Carlton: Blackwell.

Järv, Risto 2008. Real places and countries in the fairy tale world. - Koht ja paik / Place and Location. Studies in Environmental Esthetics and Semiotics VI. Toim Eva Näripea, Virve Sarapik, Jaak Tomberg, lk 275-284.

Järv, Risto 2010. Muinasjutt ja turismireis. - Keel ja Kirjandus, nr 8-9, lk 628638.

Jürgen s o n, Aivar 2007. Siberlaste identiteedi kujunemine ja selle üks poliitilisi avaldumisvorme - oblastnike liikumine. - Acta Historica Tallinnensia, kd 11, lk 30-47.

Ka plins ki, Jaan 1965. Jäljed allikal. Tallinn: Eesti Raamat.

Ka plin s ki, Jaan 1998. Öölinnud, öömõtted. Yölintuja, yöajatuksia. Night birds, night thoughts. Luuletusi 1995-1997. Tallinn: Vagabund.

Ka plin s ki, Jaan 2000. Kirjutatud. Valitud luuletused. Tallinn: Varrak.

Ka plin ski, Jaan 2005. Sõnad sõnatusse. Инакобытие. Tallinn: Vagabund.

Ka plinski, Jaan 2008. Teiselpool järve. Tallinn: Tänapäev.

Ka plinski, Jaan 2009. Teispool sinist taevast. Tallinn: AS Ajakirjade Kirjastus.

Kaplinski, Jaan. Vercingetorix kõneleb ordumeistriga. http://jaan.kaplinski. com/opinions/Vercingetorix.html

Karjalain en, Pauli Tapani 2002. Landscape's Ways. - Koht ja paik / Place and Location II. (Proceedings of the Estonian Academy of Arts 10.) Toim Virve Sarapik, Kadri Tüür, Mari Laanemets. Tallinn: Eesti Kunstiakadeemia, lk 131-138.

Ke p p, Õnne 2012. Eesti luule taevalaotus. Tähekujundi funktsioonid ja semantiline tüpoloogia XIX sajandi teisel poolel ja XX sajandi alguses. - Paar sammukest XXVI. Universumit uudistades. (Eesti Kirjandusmuuseumi aastaraamat 2009.) Koost Mare Kõiva, Andres Kuperjanov. Tartu: EKM Teaduskirjastus, lk 189-201.

Lattik, Margus 2014. Loodus, igavik ja argipäev. Postkoloniaalne identiteediloome Jaan Kaplinski ja Derek Walcotti luules. - Keel ja Kirjandus, nr 5, lk 372-382.

Moretti, Franco 1999. Atlas of the European Novel 1800-1900. London-New York: Verso.

Relph, Edward 1976. Place and Placelessness. London: Pion.

S a lu m ets, Thomas 2014a. Kaplinski tasakaal. - T. Salumets, Mõju mõnu. Tartu: Tartu Ülikooli Kirjastus, lk 50-66.

Salumets, Thomas 2014b. Lõhenenud teadvus: Jaan Kaplinski ning Euroopasisese postkolonialismi pärand Eestis. - T. Salumets, Mõju mõnu. Tartu: Tartu Ülikooli Kirjastus, lk 302-324.

Salumets, Thomas 2014c. Unforced Flourishing: Understanding Jaan Kaplinski. Montreal-Kingston: McGill-Queen's University Press.

Sh ake s pe ar e, William 1975. Hamlet. Tlk Georg Meri. Tallinn: Eesti Raamat

Tu an, Yi-Fu 1981. Space and Place. The Perspective of Experience. Minneapolis: University of Minnesota Press.

Undusk, Jaan 2009. Eesti lugu: Mats Traat „Tants aurukatla ümber”. - Eesti Päevaleht 22. V. 


\section{Kaplinski's far-away spaces}

Keywords: Jaan Kaplinski, contemporary Estonian poetry, space, distance

Triggered by the image suggested in Hamlet that even while bounded in a nutshell it is still possible to consider oneself the king of infinite space, the article attempts to chart the reach of the dimension of the far-away space in Jaan Kaplinski's poetry. The point of departure is found in the chrestomatic works on space and place in humanistic geography that underscore the nature of space as "amorphous and intangible and not an entity that can be directly described and analysed" (Relph 1976: 8). Thus, while lacking stability and connoting with openness, freedom and mobility, space is made meaningful by places for which it creates a context.

In Kaplinski's poems four major kinds of far-away spaces can be detected, each signalled by the type of places embedded in them. Firstly, there is the cosmic space that can be described by evoking the names of celestial bodies and constellations; there is an awareness that distances in this type of space are measured in light years. Secondly, a type of space appears that bears features of the Fairy land described by folklorists, such as being vaguely located somewhere unmeasureably far away with scarce toponymic reference mostly used just to signal distance, and being possibly surrounded by a boundary that cuts it off from the everyday world. Tropes emerging in connection with this space are mountains, the desert and the sea.

Thirdly, there is a kind of space constructed by places and regions on the actual political world map, usually sites of tension and conflict an awareness of which may explictly come from the media. A prominent subcategory, directly connected with map-making and the related naming of foreign places, is (post)colonial space. Also other culturally or politically mediated spaces are gathered under this umbrella. And finally, there is the far-off dimension of the world that the persona can relate to as a traveller, either by having visited certain places or dreaming of the possibility.

What also emerges in the course of the discussion is that the spatial types appear already in Kaplinski's slim first collection and are elaborated in a more individual manner throughout the poet's later oevre.

Ene-Reet Soovik (b. 1968), lecturer at the Department of English, University of Tartu; editor of the journal Sign Systems Studies, ene-reet.soovik@ut.ee 